J Dev Life Course Criminol. 2017 September ; 3(3): 304-325. doi:10.1007/s40865-017-0066-5.

\title{
The Role of Self-Regulation in Academic and Behavioral Paths to a High School Diploma
}

\author{
Christopher Cambron ${ }^{1}$, Rick Kosterman ${ }^{1}$, Richard F. Catalano ${ }^{1}$, Katarina Guttmannova ${ }^{2}$, \\ Todd I. Herrenkohl ${ }^{1}$, Karl G. Hill ${ }^{1}$, and J. David Hawkins ${ }^{1}$ \\ ${ }^{1}$ Social Development Research Group, School of Social Work, University of Washington \\ ${ }^{2}$ Department of Psychiatry and Behavioral Sciences, University of Washington
}

\section{Introduction}

Failure to obtain a high school diploma has been linked to substantial societal costs emanating from reduced economic success and negative physical and mental health outcomes as well as increased substance abuse, criminal behavior, and likelihood of receiving welfare across the life course (Battin-Pearson et al. 2000; Lansford et al. 2016; Maynard et al. 2015; Freeman and Simonsen 2015). High school completion rates in America have garnered national attention, and identification of intervention points to increase the number of students obtaining diplomas remains a priority among practitioners and researchers alike (Lansford et al. 2016; Freeman and Simonsen 2015). While some students may drop out of high school with no plan to return, many students engage in a months- or years-long process that may include periods of both disengagement and reengagement with high school. While these students often struggle academically, it is important to recognize that multiple factors may contribute to student success in achieving a high school diploma (McEvoy and Welker 2000; Rumberger 2011). Paths that lead to high school failure often include illegal substance use, delinquency, and deviant peer affiliations (Wang and Fredricks 2014; Battin-Pearson et al. 2000; Alexander et al. 1997; Rumberger 2011), and may reflect risk factors that began taking shape prior to high school (Ensminger and Slusarcick 1992; Newcomb et al. 2002). Studies examining family and school contexts have also found that poor bonds with schools, stressful family environments, weak parental support for education, and socioeconomic disadvantage may negatively influence academic attainment through interrelationships with increased antisocial behavior or reduced academic performance (Battin-Pearson et al. 2000; Newcomb et al. 2002; Henry et al. 2012). More recently, researchers have suggested that poor self-regulation may be intricately linked to both academically and behaviorally oriented paths to academic attainment (Isquith et al. 2004; Masten et al. 2005). Drawing on research from multiple disciplines, we examined the potential role of self-regulation in both academic and behavioral paths to achieving a high school diploma. We are not aware of any study that has incorporated all of these key factors into a longitudinal model of academic attainment.

Correspondence: Christopher Cambron, ccambron@uw.edu, Social Development Research Group, School of Social Work, University of Washington, 9725 Third Ave NE, Suite \#401, Seattle WA 98115. 


\section{The Importance of Self-Regulation}

Self-regulation can be succinctly defined as "control of attentional, emotional, and behavioral impulses," and is regularly cited as a key component of social adaptation (VegaFernandez et al. 2014; Duckworth and Carlson 2013). As such, poor self-regulation is most easily observed though difficulty sustaining attention, inability to effectively regulate behavioral impulses, and challenges in handling strong emotions through socially appropriate means. Although researchers have treated these three components of selfregulation as distinct psychological processes, self-regulation scholars have contended that they comprise a higher order, multidimensional process (de Ridder et al. 2012; Duckworth and Carlson 2013; McAuley et al. 2010). These processes that constitute self-regulation are thought to be an outgrowth of executive functions operating in the prefrontal cortex of the brain (McAuley et al. 2010). Neuropsychological tests indicating deficits in executive functions are typically associated with attention and planning problems as well as emotion and behavior regulation difficulties (Ogilvie et al. 2011). Based on these findings, poor selfregulation, or low self-control, is regularly cited by researchers as evidence of deficits in executive functions in the absence of explicit neuropsychological tests of executive functions (Moffitt et al. 2011; Felson and Staff 2006; Biederman et al. 2004; Beaver et al. 2007). There is, however, an ongoing debate regarding the extent to which Gottfredson and Hirschi's (1990) original conceptualization of self-control, well known to criminologists, overlaps with self-regulation as deployed by psychologists, or the underlying construct of executive function as described by neuroscientists (Beaver et al. 2007; Duckworth and Kern 2011; Cauffman et al. 2005). Recent meta-analyses published in journals oriented towards both criminologists (Vazsonyi et al. 2017) and psychologists (Duckworth and Kern 2011) have specifically highlighted the substantial overlap between measures of self-control and self-regulation. In these meta-analyses, the conceptual overlap was deemed strong enough to warrant the inclusion of studies focused on both self-regulation and self-control. While questions about exact measurement and appropriate description of underlying processes are yet to be fully resolved, self-regulation and self-control have become transdisciplinary constructs often used interchangeably across and within research studies (de Ridder et al. 2012; Duckworth and Kern 2011).

Given its importance to numerous disciplines including psychology, criminology, education, and neuroscience, researchers have amassed considerable evidence that deficits in executive functions and the associated lack of self-regulation are critically important for both academic problems and academic success (Hughes 2011; Diamond 2013; Duckworth and Carlson 2013; Moffitt et al. 2011; Lengua et al. 2001). In addition, research with adolescents has demonstrated links between both executive function deficits and poor self-regulation and increased behavioral problems as measured by aggression, bullying, delinquency, and illegal substance use, as well as clinical diagnoses such as conduct disorder, oppositional defiant disorder, attention deficit hyperactivity disorder, and substance use disorders (Banich 2009; Ogilvie et al. 2011; Best et al. 2011; Best and Miller 2010). Meta-analyses have confirmed strong and stable associations between executive function impairments and antisocial behavior (Morgan and Lilienfeld 2000; Ogilvie et al. 2011). Meta-analyses have also confirmed consistent relationships between poor self-regulation or self-control and 
delinquency, alcohol use, and reduced academic performance (de Ridder et al. 2012; Pratt and Cullen 2000; Vazsonyi et al. 2017). Antisocial Behavior, Family Factors, and Academics

A great deal of theoretical and empirical work has been dedicated to understanding the etiology and development of antisocial behavior in childhood and adolescence (Byrd et al. 2014; Hawkins et al. 1992; Catalano and Hawkins 1996; Patterson et al. 1989; Moffitt 2003; Gottfredson and Hirschi 1990). Fewer studies, however, have examined the role that antisocial behavior plays in academic attainment (Battin-Pearson et al. 2000; Newcomb et al. 2002; Rumberger 2011). Students struggling academically are often considered at risk for illegal substance use, delinquency, and other problem behaviors (Felson and Staff 2006; Hawkins et al. 1992; McEvoy and Welker 2000). While some have proposed bidirectional relationships between academic performance and delinquency (Felson and Staff 2006; McEvoy and Welker 2000), interventions aimed at improving academic performance have shown some evidence that improving academic performance may subsequently reduce delinquency and other problem behaviors (Najaka et al. 2001). Felson and Staff (2006) explicitly set out to explain the relationship between academic performance and delinquency in a nationally representative sample. While they found a strong bivariate relationship between academic performance and delinquency, an academically based measure of student self-regulation accounted for about half of that relationship when included in the model (Felson and Staff 2006).

Researchers have also suggested that relationships between antisocial behavior and academic performance must be assessed within the context of school environments (Wang and Fredricks 2014; McEvoy and Welker 2000). Multiple studies have demonstrated that bonding to and engagement with school is important for both antisocial behavior and academic success (Catalano et al. 2004; Wang and Fredricks 2014; Henry et al. 2012). Wang and Fredricks (2014) found reciprocal relationships between school engagement and problem behaviors, including delinquency and substance use, from ages 12 to 17 . Both reduced engagement and increased problem behaviors ultimately predicted a higher likelihood of later school dropout. Similarly grounded theoretical and empirical work suggests that negative feedback loops develop between early self-regulation problems, poor academic performance, and low school engagement. In school settings, school disengagement in conjunction with poor self-regulation and low grades eventually contributes to school failure (Isquith et al. 2004; Blair and Diamond 2008). Further support for interrelationships among poor self-regulation, antisocial behavior, and weak prosocial bonds has come from multiple criminological studies examining the etiology of antisocial behavior (Hay et al. 2013; Wright et al. 1999; Longshore et al. 2005).

To contextualize relationships between academic performance and antisocial behavior in the current study, we employ a theoretically and empirically established measure of school prosocial development that considers both the processes by which school bonding occurs and the strength of the bond itself (Catalano and Hawkins 1996). This construct is borrowed from the social development model (SDM), a general theory of human behavior that describes the etiology of both prosocial and antisocial behaviors and organizes risk and protective factor research into a coherent framework (Hawkins et al. 1992; Catalano and Hawkins 1996). The SDM synthesizes the strongest empirically supported components of 
three prominent criminological theories: control theory (Hirschi 1969), social learning theory (Bandura and McClelland 1977), and differential association theory (Sutherland 1973; Matsueda and Heimer 1987). Prosocial developmental processes that lead a student to bond with his or her school have been shown to be important for inhibiting substance use, delinquency, antisocial peer affiliations, and violence (Catalano et al. 2004). A meta-analysis by Najaka and colleagues (2001) found that school bonding, compared to multiple other risk factors, was the most salient predictor of problem behaviors among adolescents.

The quality and strength of relationships among families also plays a critical role in the development of antisocial behavior and, in turn, academic success among adolescents. Children living in families characterized by high levels of conflict, poor parental management and monitoring, and weak bonds among families members have been shown to be at increased risk for engaging in antisocial behavior and substance use (Deng and Roosa 2007; Kosterman et al. 2004). The SDM hypothesizes that family social development processes are most salient during childhood and may lose some of this salience as children develop stronger bonds with peers and schools throughout adolescence. Early family social development remains a key predictor of the content and quality of later school and peer social development processes which become more prominent during high school (Catalano and Hawkins 1996). Intervention studies have shown that family relational factors may be particularly salient for inhibiting antisocial behavior across the transition from middle to high school (Van Ryzin et al. 2012). Apart from family relationship quality, multiple studies have found that higher family socioeconomic status (SES) is associated with increased academic attainment (Newcomb et al. 2002; Ensminger and Slusarcick 1992). Meta-analyses have also demonstrated that higher family SES, as measured by family income or parental education, is strongly associated with improved academic performance (Sirin 2005).

It is important to note that, while the factors detailed above may impact both academic and behavioral paths to obtaining a high school degree, there also may be important differences for students who adhere to more traditional paths to a high school diploma. Studies comparing students obtaining a high school diploma to those completing the General Education Development (GED) equivalency exam have shown that students obtaining a diploma have more future economic success (Lansford et al. 2016). While GED and high school diploma achievers typically perform at similar levels on intelligence tests, students failing to obtain a high school diploma may lack important non-cognitive skills related to planning and social adaptation (Masten et al. 2005). These same skills make up core dimensions of self-regulation (Lengua et al. 2001) and are likely one way that antisocial behavior is related to lower academic attainment (Duckworth and Carlson 2013). As such, self-regulation may represent a point of possible intervention to improve academic attainment through multiple avenues. These findings lend further credence to considering the unique contribution of academic and behavioral paths to obtaining a high school diploma.

\section{Methods}

\section{Goals and Hypotheses}

The primary goal of this study is to investigate the role of self-regulation in both academic and behavioral paths to obtaining a high school diploma. We expect to find an academic path 
whereby students who are successful during middle school are more likely to remain successful during high school and, in turn, have an increased likelihood of obtaining a high school diploma. We also expect to find a behavioral path whereby students with poor selfregulation during middle school will become more involved in antisocial behavior during high school and, in turn, experience a reduced likelihood of obtaining a high school diploma. The extent to which these two paths overlap is an important question to be addressed here. Evidence exists to suggest that poor middle school self-regulation may predict lower high school academic performance, or poor middle school academic performance may predict increased high school antisocial behavior. Given that family and school factors may potentially confound either of these paths to obtaining a high school diploma or exert their own direct influence on obtaining a high school diploma, we assess both academic and behavioral paths in the context sociodemographic factors, low family functioning, and school prosocial development. Figure 1 provides a conceptual diagram of the key hypothesized relationships to be examined in this study.

\section{Sample Characteristics}

Data were drawn from the Seattle Social Development Project (SSDP), a longitudinal, theory-driven study originating in 18 Seattle elementary schools over-representing high crime neighborhoods. SSDP began conducting in-person interviews in 1985 with 808 students in the fifth grade and their parents and teachers. The 808 respondents accounted for $77 \%$ of the 1,053 fifth-grade students invited to participate in the study. Surveys were conducted in the fall of 1985, the spring of 1986, and then annually through 10th grade. Students were surveyed again in 12th grade and every 3 years subsequently through age 33 . Retention rates remained consistently high across waves of data collection and consisted of $96 \%$ of the still-living sample at age 21 . Of the 808 participants, $49 \%$ were female, $46 \%$ were European American, 24\% were African American, 21\% were Asian American, and 9\% were Native American or other ethnic group. Fifty-two percent of the sample were low income as indicated by eligibility for free or reduced price lunch from grades 5 to 7 . This study employs prospectively gathered data from grades 5 through 10 and retrospective reports of educational attainment by age 18 from four waves of data collection from ages 21 to 30 .

High School Diploma-Obtaining a high school diploma was indicated by the question "Do you have a high school diploma, GED, or neither" asked of participants at age 30. High school diploma was coded as 1 and all others were coded as 0 . Participants with missing data on this question were assessed by a second question "What is the last year of schooling that you have completed," recorded at ages 21, 24, 27, and 30. Response options indicating less than high school diploma from ages 21 to 30 were coded as 0 . Because 16 participants provided ambiguous information regarding high school graduation (i.e., reported not obtaining a high school diploma after previously reporting obtaining a high school diploma), two versions of the high school diploma variable were constructed (one with those 16 scored as obtaining a diploma and one scored that they did not). Sensitivity tests demonstrated no substantive changes in coefficients of interest when testing two versions of the high school diploma variable. Seventy percent of the analysis sample indicated obtaining a high school diploma. 
Poor Self-Regulation-The Child Behavior Checklist (CBCL) is a widely employed measure of social, emotional, and behavioral health during childhood (Achenbach and Edelbrock 1986). It is broadly organized into internalizing and externalizing symptoms that relate to a range of childhood problems and clinical diagnoses (Maynard et al. 2015). Numerous studies have employed items from the CBCL to measure self-control or selfregulation (Biederman et al. 2004; Meldrum and Barnes 2016; Riccio and Gomes 2013; Meldrum et al. 2013; Anderson 2002; Wilens et al. 2011; Zhou et al. 2012; Best and Miller 2010). These studies have typically constructed a unidimensional measure of self-control with scale reliabilities ranging from .66 (Best and Miller 2010) to .91 (Anderson 2002). However, the current study operationalized self-regulation as a multidimensional construct in line with theoretical and empirical agreement among researchers that self-regulation has multiple distinct components and that these components constitute a higher order process (McAuley et al. 2010; Duckworth and Carlson 2013).

Given the strong theoretical and empirical relationships between self-regulation and executive function, we drew from the executive function literature to construct a multidimensional measure of self-regulation for this study that was guided conceptually by a prominent behavioral measure of executive function. The Brief Inventory of Executive Functioning (BRIEF) scale is a reliable and valid observational survey that assesses behavioral manifestations of executive function through teacher and parent reports of everyday child behaviors (Gioia et al. 2002). The subscales of the BRIEF load onto a threefactor solution denoted as metacognition, behavior regulation, and emotion regulation (Gioia et al. 2002; Egeland and Fallmyr 2010). To construct a multidimensional measure of selfregulation, items from the Teacher Report version of the CBCL were matched on face validity to items from the BRIEF, and organized into three subscales indicating metacognition, behavior regulation, and emotion regulation. Results of confirmatory factor analysis (CFA) yielded adequate fit for a three-factor solution $\left(\chi^{2}(116)=466, \mathrm{CFI}=.98\right.$, RMSEA = .06). CBCL item descriptions and CFA results are reported in Table 1. Mean scales for metacognition (MC, $a=0.91$ ), behavior regulation (BR, $a=0.93$ ), and emotion regulation $(E R, a=0.85)$ were constructed within each grade and averaged across grades 5 through 8. All items were standardized within grade and cases with half or more items for all three standardized mean scales were considered valid cases. Each CBCL question asks about the presence of a problem behavior and offers item responses rated as $0=$ "not true," $1=$ "somewhat or sometimes true," and 2 = "very true or very often true." Therefore, higher scores on each scale indicated more severe problems on that scale.

Academic Performance-Measures of academic performance were computed from three sources: school-reported grade point average (GPA), California Achievement Test (CAT) scores (Wardrop 1989), and self-reported grades. All measures were standardized within grade and averaged at each grade. Cases with at least two of three academic measures were given a score on the annual measure and cases with less than two sources of data were set to missing at that year. Composite measures of the average of grades 5 through 8 represented middle school academic performance while composite measures of grades 9 and 10 represented high school academic performance. 
Antisocial Behavior-Antisocial behavior was assessed with a latent variable composed of self-reported delinquency, substance use, and peer antisocial development. Each measure was averaged across grades 9 and 10 prior to the construction of the latent factor for high school antisocial behavior. An identical latent factor was created at grade 5 to measure early antisocial behavior. The delinquency measure was derived from a series of questions concerning minor acts of delinquency such as drawing graffiti or stealing items worth less than $\$ 5$; moderate acts including property destruction or theft of items worth up to $\$ 50$; or severe acts such as selling drugs, using a weapon to get something, or breaking and entering. In line with previous investigations seeking to capture both the chronicity and severity of adolescent delinquency, items were weighted by severity: 1 for minor acts, 2 for moderate acts, and 3 for severe acts (Gilman et al. 2015). Substance use was measured by self-reports of alcohol, tobacco, and marijuana use in the past month. Measures of substance use and delinquency were log transformed to reduce skewness and kurtosis and standardized within grade. Peer antisocial development was measured as a composite of self-reports of antisocial friends and opportunities for antisocial behavior. The antisocial friend measure was derived from a series of questions about whether closest friends got in trouble with teachers, did things that would get them in trouble with police, participated in gangs, used alcohol or marijuana, or were suspended or expelled from school. The antisocial opportunities measure was indicated by questions about whether respondents were asked to do things they knew would get them in trouble, were expected by friends to do these things, or were asked to join gangs. All measures were standardized within grade.

School Prosocial Development-School prosocial development was assessed with a latent variable composed of school opportunities, rewards, and bonds. Empirical tests of the SDM have demonstrated the utility of modeling social development processes as a latent variable (Catalano et al. 2005). Each individual construct was derived from a range of positive and negative responses gauging student perceptions of and interactions with teachers, peers, and organizations or clubs within the school from grades 9 and 10. Similar measures of school opportunities, involvement, rewards, and bonds have been employed in multiple studies (Abbott et al. 1998; Catalano et al. 2005). Example questions for school bonding include: "I like school," "I like my teacher this year," and "Most mornings, I look forward to going to school." Example questions for school opportunities include: "Many chances for students in my school to get involved in sports, clubs and so forth," and "Even students who don't do well in school help decide things." Example questions for school rewards include: "My teacher embarrasses me for not knowing the right answer" and "My teachers praise or compliment me when I work hard." All items other than numerical response questions were coded as $0=$ NO!, $1=$ no, $2=$ yes, and $3=$ YES!. Standardized mean scales whereby higher scores indicated higher levels of opportunities, rewards, and bonds in each year were averaged across grades 9 and 10 .

Poor Family Functioning-Measures of high family conflict, poor family management, and weak family bonds similar to those employed by tests of the SDM were used to create a latent factor of poor family functioning (Kosterman et al. 2004). Example questions for family conflict include "When my parents and I disagree, we talk things out" and "People in my family often criticize each other." Example questions for family management include 
"When you are away from home, do your parents know where you are and who you are with," and "The rules in my family are clear." Family bonding was indicated by whether students wanted to be like their mother or father and if they shared their thoughts and feelings with family members. Each question offered the four response options of YES!, yes, no, and NO!; all responses were coded such that higher scores reflected poorer family functioning. Standardized mean scales were constructed within grade and averaged across grades 5 through 8 .

Family Socioeconomic Resources-Family income, parental education, and being a recipient of free or reduced price lunch were used to constitute a latent factor of family socioeconomic resources. Family income was reported by parents and measured at each grade by a seven-category question with annual income response options ranging from less than $\$ 5,000$ to greater than $\$ 40,000$. Parent education was reported by parents at each grade and coded such that $1=$ Bachelor's degree or higher and $0=$ less than a college degree. The maximum of mother's and father's education was taken at each grade and averaged across grades. Eligibility for free or reduced price lunch from grades 5 through 7 was reverse coded as $0=$ eligible and $1=$ ineligible for the purposes of consistency with parental education and family income.

Gender and Ethnicity-Dichotomous indicators for gender (female $=1$, male $=0$ ) and African American, Asian American, and Native American ethnicity were included in all structural models, with European American serving as the referent group for ethnicity variables.

\section{Analysis}

A structural equation model was tested using probit regression for binary outcomes in Mplus version 7.4 (Muthén and Muthén 2012). The weighted least squares mean- and varianceadjusted estimator was employed, and missing data was handled by full information maximum likelihood. Data were present for over $96 \%$ of possible data points across 25 variables used in these analyses $(19,470$ out of 20,200$)$ and over $98 \%$ of possible data points for the latent mediators. Sixty missing data patterns were identified, with one pattern being no missingness. Previously published studies with this sample have shown the effectiveness of maximum likelihood-based missing data strategies given the low incidence of missingness among the 808 respondents (Hawkins et al. 1997; Kosterman et al. 2001). Model fit was assessed using comparative fit index (CFI) and the root mean square error of approximation (RMSEA; Browne and Cudeck 1993), and mediation tests were conducted using the Model Indirect command in Mplus.

\section{Results}

The structural equation model explained $61 \%$ of the variance in obtaining a high school diploma. Results for paths of primary interest are discussed below. Coefficients for all paths are provided in Table 3 and results of mediation tests are provided in Table 4. As expected, improved academic performance during middle school significantly predicted improved academic performance during high school (standardized coefficient of .61). Both middle and 
high school academic performance uniquely predicted a significantly higher likelihood of obtaining a high school diploma (standardized coefficients of .32 and .20, respectively). Forty-nine percent of the variance in high school academic performance was explained by the model. Poor self-regulation during middle school significantly predicted increased antisocial behavior during high school after controlling for early antisocial behavior (standardized coefficient of .24). In turn, high school antisocial behavior significantly predicted lower likelihood of obtaining a high school diploma (standardized coefficient of 39). Forty-six percent of the variance in antisocial behavior was explained by the model. Results indicated that school prosocial development during high school showed no direct relationship to obtaining a high school diploma and it was negatively related to antisocial behavior and positively related to academic performance (standardized coefficients of -.43 and .16, respectively). Poor self-regulation significantly predicted lower levels of school prosocial development (standardized coefficient of -.25). Twenty-eight percent of the variance in school prosocial development was explained by the model. Results indicated a significant direct relationship between higher family socioeconomic resources and an increased likelihood of obtaining a high school diploma (standardized coefficient of .26). No direct effect on the likelihood of obtaining a high school diploma was noted for poor selfregulation during middle school, poor family functioning during middle school, early antisocial behavior, gender, or ethnicity.

Mediation tests found that middle school academic performance operated indirectly through high school academic performance to influence the likelihood of obtaining a high school diploma. Poor self-regulation in middle school operated indirectly through high school antisocial behavior to influence the likelihood of obtaining a high school diploma. A bivariate correlation of -.49 between poor self-regulation and obtaining a high school diploma was fully mediated by the variables in the model. Significant mediation was not found for family socioeconomic resources through either academic performance or antisocial behavior in high school. Middle school academic performance was not found to operate indirectly through high school antisocial behavior, and middle school poor selfregulation was not found to operate indirectly through high school academic performance.

\section{Discussion}

The results of this study provide support for conceptualizing unique academic and behavioral paths toward obtaining a high school diploma. Students who were successful academically during middle school were more likely to continue that success and achieve a high school diploma. Students that struggled with poor self-regulation during middle school were more likely to engage in antisocial behavior during high school and reduced their chances of obtaining a high school diploma. Both paths were considered concurrently and in the context of low family functioning, school prosocial development, early antisocial behavior, and sociodemographic factors. To our knowledge this is the first longitudinal study of academic attainment to examine self-regulation as a precursor to antisocial behavior and, ultimately, an important factor for obtaining a high school diploma (Newcomb et al. 2002). Findings support conceptualizing poor self-regulation as a risk factor for antisocial behavior (Fishbein 2000; Freeman and Simonsen 2015), antisocial behavior as a risk factor for high 
school failure (Rumberger 2011), and antisocial behavior as an important link between selfregulation and academic attainment.

From a prevention science perspective, the results of the study highlight addressing poor self-regulation as a possible intervention point for those seeking to prevent delinquency and substance use and, in turn, improve rates of high school graduation. Improving selfregulation may also increase school prosocial development, which has been shown to protect against antisocial behavior (Catalano et al. 2004; Greenberg et al. 2007). Previous research has identified a range of activities, training techniques, and school-based programs associated with improvements in executive functions and multiple dimensions of selfregulation in children (Diamond 2012; Diamond and Lee 2011; Piquero et al. 2016). The strongest and most consistent evidence of success has been shown for computer-assisted training and aerobic exercise enhancing metacognitive functions; martial arts training and mindfulness practice supporting behavioral regulation; and guided, dramatic play helping with development of socially appropriate responses (Diamond 2012; Diamond and Lee 2011). Classroom-based programming such as Tools of the Mind (Barnett et al. 2008; Bodrova and Leong 2001) and Promoting Alternative Thinking Strategies (Riggs et al. 2006; Greenberg et al. 1995) seek to enhance executive functions and self-regulation using specific intervention strategies. Rigorous evaluations of both programs have shown promising improvement in executive function, self-regulation, and related skills (Diamond and Lee 2011). The mounting evidence on the importance of self-regulation recently produced multiple federal reports highlighting the key role of self-regulation in academic success (Murray et al. 2015).

Results showing significant paths from poor self-regulation during middle school to antisocial behavior and school prosocial development during high school concur with notions that the road to high school dropout begins well before dropout occurs, providing significant prevention opportunities (Alexander et al. 1997). We also find evidence of this in a strong and significant direct path from middle school academic performance to obtaining a high school diploma after accounting for a range of other factors. Some research would suggest that this unmediated path from early academics to high school graduation may relate to expectations of academic attainment that adults and teachers develop about children and students develop about themselves early in their academic careers (Battin-Pearson et al. 2000; Alexander et al. 1997). Educational researchers have implicated self-regulation in the processes by which early academic success fosters school engagement and keeps students on track to graduation (Blair and Diamond 2008). The direct path from family SES during middle school suggests that economically based parental support for education during middle school can have lasting impacts on academic attainment.

Our model examined the concurrent association between poor self-regulation and middle school academic performance (standardized covariance of -.69). However, given results of empirical studies showing the importance of self-regulation in academic attainment, we conducted an additional mediation test whereby poor self-regulation predicted middle school academic performance and, in turn, obtaining a high school diploma (results available upon request). Results indciated significant mediation of the association between poor self- 
regulation and obtaining a high school diploma by middle school academic performance providing further evidence of the importance of self-regulation for adolescent development.

This study also presents a measure of poor self-regulation derived from the CBCL that may prove useful to other researchers interested in relationships of early self-regulation and later life outcomes. Given the inclusion of the CBCL in many longitudinal datasets and the importance of self-regulation and related constructs for academic, social, behavioral, and occupational success (Diamond 2013; Duckworth and Carlson 2013), other researchers may seek to employ this measure in their own work. Many longitudinal studies containing the CBCL were initiated long before the development and standardization of measures of selfregulation or executive function. The measure employed here builds upon unidimensional measures of self-control or self-regulation found in many studies and offers a multidimensional measure of self-regulation in line with current theories of executive function (Duckworth and Carlson 2013). As a teacher report measure, the CBCL may ameliorate concerns that respondents are reluctant to accurately report poor self-regulation (Gottfredson and Hirschi 1990). Further research is necessary to validate a multidimensional measure of self-regulation derived from the $\mathrm{CBCL}$, investigate its psychometric properties, and to examine its relationship to the BRIEF and other established measures of executive function or self-regulation.

Caution should be taken in generalizing these findings beyond the current sample. SSDP oversampled high-crime neighborhoods and, given established links between executive function development and social environments, further investigation is needed. In particular, numerous studies have identified strong and consistent links between lower SES and neurocognitive deficits (Nesbitt et al. 2013; Hackman and Farah 2009; Sarsour et al. 2010; Hackman et al. 2010; Noble et al. 2005). The stresses of poverty are thought to exhibit structural effects on brain development that diminish executive functions and condition stress reactivity responses that inhibit the application of self-regulation (Blair 2010). Researchers have suggested that SES differences may have especially pronounced effects on the metacognitive processes beyond their typical effects on neurological development and, in turn, inhibitory control (Lawson et al. 2014). In this study, we do find a moderate inverse relationship between poor self-regulation and higher family SES (standardized coefficient of -.23). Paired with the direct effect of family socioeconomic resources on increasing the likelihood of obtaining a high school diploma, our results suggest future studies investigating poor self-regulation as a link between family SES and academic attainment are needed. Further research into the development of self-regulation in children from a variety of socioeconomic backgrounds would offer more perspective on this question. Overall, we expect that future research will continue to show the central role of self-regulation in successful child and adolescent development. We also expect that researchers and practitioners alike will continue to refine our understanding of how to best support selfregulation in children to support healthy developmental outcomes.

\section{Acknowledgments}

Data collection for this study was supported by grants from the National Institute on Drug Abuse (5R01DA003721 and 5R01DA033956). Support was provided a National Poverty Research Center Dissertation Fellowship awarded by the Institute for Research on Poverty at the University of Wisconsin - Madison with funding from the Office of 
the Assistant Secretary for Planning and Evaluation, U.S. Department of Health and Human Services, Cooperative Agreement number AE00103. Support was provided by a Eunice Kennedy Shriver National Institute of Child Health and Human Development research infrastructure grant, No. R24HD042828; and training grant No. T32HD007543 to the Center for Studies in Demography and Ecology at the University of Washington. The opinions and conclusions expressed herein are solely those of the author and should not be construed as representing the opinions or policy of any agency of the Federal government. The authors would like to thank Paula Nurius and Amelia Gavin for their helpful comments on earlier drafts.

\section{References}

Abbott RD, O'Donnell J, Hawkins JD, Hill KG, Kosterman R, Catalano RF. Changing teaching practices to promote achievement and bonding to school. American Journal of Orthopsychiatry. 1998; 68(4):542-552. [PubMed: 9809114]

Achenbach TM, Edelbrock CS. Manual for the Teacher's Report Form and Teacher Version of the Child Behavior Profile. Burlington, VT: University of Vermont Press; 1986.

Alexander KL, Entwisle DR, Horsey CS. From first grade forward: early foundations of high school dropout. Sociology of Education. 1997; 70(2):87-107.

Anderson P. Assessment and development of executive function (EF) during childhood. Child Neuropsychology. 2002; 8(2):71-82. [PubMed: 12638061]

Bandura A, McClelland DC. Social learning theory. Englewood Cliffs, NJ: Prentice Hall; 1977.

Banich MT. Executive function: the search for an integrated account. Current Directions in Psychological Science. 2009; 18(2):89-94.

Barnett WS, Jung K, Yarosz DJ, Thomas J, Hornbeck A, Stechuk R, et al. Educational effects of the Tools of the Mind curriculum: a randomized trial. Early Childhood Research Quarterly. 2008; 23(3): 299-313.

Battin-Pearson S, Newcomb MD, Abbott RD, Hill KG, Catalano RF, Hawkins JD. Predictors of early high school dropout: a test of five theories. Journal of Educational Psychology. 2000; 92(3):568582.

Beaver KM, Wright JP, DeLisi M. Self-control as an executive function: reformulating Gottfredson and Hirschi's parental socialization thesis. Criminal Justice and Behavior. 2007; 34(10):1345-1361.

Best JR, Miller PH. A developmental perspective on executive function. Child Development. 2010; 81(6):1641-1660. [PubMed: 21077853]

Best JR, Miller PH, Naglieri JA. Relations between executive function and academic achievement from ages 5 to 17 in a large, representative national sample. Learning and Individual Differences. 2011; 21(4):327-336. [PubMed: 21845021]

Biederman J, Monuteaux MC, Doyle AE, Seidman LJ, Wilens TE, Ferrero F, et al. Impact of executive function deficits and attention-deficit/hyperactivity disorder (ADHD) on academic outcomes in children. Journal of Consulting and Clinical Psychology. 2004; 72(5):757-766. [PubMed: 15482034]

Blair C. Stress and the development of self-regulation in context. Child Development Perspectives. 2010; 4(3):181-188. [PubMed: 21779305]

Blair C, Diamond A. Biological processes in prevention and intervention: the promotion of selfregulation as a means of preventing school failure. Development and Psychopathology. 2008; 20(3):899-911. [PubMed: 18606037]

Bodrova E, Leong DJ. Tools of the Mind: a case study of implementing the Vygotskian approach in American early childhood and primary classrooms. Innodata Monographs 7. Geneva: International Bureau of Education; 2001.

Browne MW, Cudeck R. Alternative ways of assessing model fit. In: Bollen KA, Long JS, editorsTesting structural equation models. Newbury Park, CA: Sage; 1993. 136-136.

Byrd AL, Loeber R, Pardini DA. Antisocial behavior, psychopathic features and abnormalities in reward and punishment processing in youth. Clinical Child and Family Psychology Review. 2014; 17(2):125-156. [PubMed: 24357109]

Catalano RF, Hawkins JD. The social development model: a theory of antisocial behavior. In: Hawkins JD, editorDelinquency and crime: current theories. New York, NY: Cambridge University Press; 1996. 149-197. 
Catalano RF, Oesterle S, Fleming CB, Hawkins JD. The importance of bonding to school for healthy development: findings from the Social Development Research Group. Journal of School Health. 2004; 74(7):252-261. [PubMed: 15493702]

Catalano RF, Park J, Harachi TW, Haggerty KP, Abbott RD, Hawkins JD. Mediating the effects of poverty, gender, individual characteristics, and external constraints on antisocial behavior: a test of the social development model and implications for developmental life-course theory. In: Farrington DP, editorAdvances in criminological theory: Vol. 14. Integrated developmental and life-course theories of offending. New Brunswick, NJ: Transaction; 2005. 93-123.

Cauffman E, Steinberg L, Piquero AR. Psychological, neuropsychological and physiological correlates of serious antisocial behavior in adolescence: the role of self-control. Criminology. 2005; 43(1): 133-176.

de Ridder DTD, Lensvelt-Mulders G, Finkenauer C, Stok FM, Baumeister RF. Taking stock of selfcontrol: a meta-analysis of how trait self-control relates to a wide range of behaviors. Personality and Social Psychology Review. 2012; 16(1):76-99. [PubMed: 21878607]

Deng S, Roosa MW. Family influences on adolescent delinquent behaviors: Applying the social development model to a Chinese sample. American Journal of Community Psychology. 2007; 40(3-4):333-344. [PubMed: 17924187]

Diamond A. Activities and programs that improve children's executive functions. Current Directions in Psychological Science. 2012; 21(5):335-341. [PubMed: 25328287]

Diamond A. Executive functions. Annual Review of Psychology. 2013; 64:135-168.

Diamond A, Lee K. Interventions shown to aid executive function development in children 4 to 12 years old. Science. 2011; 333(6045):959-964. [PubMed: 21852486]

Duckworth AL, Carlson SM. Self-regulation and school success. In: Sokol BW, Grouzet FME, Müller $\mathrm{U}$, editorsSelf-regulation and autonomy: social and developmental dimensions of human conduct. New York, NY: Cambridge University Press; 2013. 208-230.

Duckworth AL, Kern ML. A meta-analysis of the convergent validity of self-control measures. Journal of Research in Personality. 2011; 45(3):259-268. [PubMed: 21643479]

Egeland J, Fallmyr O. Confirmatory factor analysis of the Behavior Rating Inventory of Executive Function (BRIEF): support for a distinction between emotional and behavioral regulation. Child Neuropsychology. 2010; 16(4):326-337. [PubMed: 20209415]

Ensminger ME, Slusarcick AL. Paths to high school graduation or dropout: a longitudinal study of a first-grade cohort. Sociology of Education. 1992; 65(2):95-113.

Felson RB, Staff J. Explaining the academic performance-delinquency relationship. Criminology. 2006; 44(2):299-319.

Fishbein D. Neuropsychological function, drug abuse, and violence: a conceptual framework. Criminal Justice and Behavior. 2000; 27(2):139-159.

Freeman J, Simonsen B. Examining the impact of policy and practice interventions on high school dropout and school completion rates: a systematic review of the literature. Review of Educational Research. 2015; 85(2):205-248.

Gilman AB, Hill KG, Hawkins JD. When is youths' debt to society paid off? Examining the long-term consequences of juvenile incarceration for adult functioning. Journal of Developmental and LifeCourse Criminology. 2015; 1(1):33-47. [PubMed: 26052482]

Gioia GA, Isquith PK, Retzlaff PD, Espy KA. Confirmatory factor analysis of the Behavior Rating Inventory of Executive Function (BRIEF) in a clinical sample. Child Neuropsychology. 2002; 8(4): 249-257. [PubMed: 12759822]

Gottfredson MR, Hirschi T. A general theory of crime. Stanford, CA: Stanford University Press; 1990.

Greenberg MT, Kusche CA, Cook ET, Quamma JP. Promoting emotional competence in school-aged children: the effects of the PATHS curriculum. Development and Psychopathology. 1995; 7(1): 117-136.

Greenberg MT, Riggs NR, Blair C. The role of preventive interventions in enhancing neurocognitive functioning and promoting competence in adolescence. In: Romer D, Walker EF, editorsAdolescent psychopathology and the developing brain: integrating brain and prevention science. New York, NY: Oxford University Press; 2007. 441-461. 
Hackman DA, Farah MJ. Socioeconomic status and the developing brain. Trends in Cognitive Sciences. 2009; 13(2):65-73. [PubMed: 19135405]

Hackman DA, Farah MJ, Meaney MJ. Socioeconomic status and the brain: mechanistic insights from human and animal research. Nature Reviews Neuroscience. 2010; 11(9):651-659. [PubMed: 20725096]

Hawkins JD, Catalano RF, Miller JY. Risk and protective factors for alcohol and other drug problems in adolescence and early adulthood: implications for substance abuse prevention. Psychological Bulletin. 1992; 112(1):64-105. [PubMed: 1529040]

Hawkins JD, Graham JW, Maguin E, Abbott R, Hill KG, Catalano RF. Exploring the effects of age of alcohol use initiation and psychosocial risk factors on subsequent alcohol misuse. Journal of Studies on Alcohol. 1997; 58(3):280-290. [PubMed: 9130220]

Hay C, Meldrum RC, Piquero AR. Negative cases in the nexus between self-control, social bonds, and delinquency. Youth Violence and Juvenile Justice. 2013; 11(1):3-25.

Henry KL, Knight KE, Thornberry TP. School disengagement as a predictor of dropout, delinquency, and problem substance use during adolescence and early adulthood. Journal of Youth and Adolescence. 2012; 41(2):156-166. [PubMed: 21523389]

Hirschi T. Causes of Delinquency. Berkley, CA: University of California Press; 1969.

Hughes C. Changes and challenges in 20 years of research into the development of executive functions. Infant and Child Development. 2011; 20(3):251-271.

Isquith PK, Gioia GA, Espy KA. Executive function in preschool children: examination through everyday behavior. Developmental Neuropsychology. 2004; 26(1):403-422. [PubMed: 15276902]

Kosterman R, Graham JW, Hawkins JD, Catalano RF, Herrenkohl TI. Childhood risk factors for persistence of violence in the transition to adulthood: a social development perspective. Violence and Victims. 2001; 16(4):355-369. [PubMed: 11506446]

Kosterman R, Haggerty KP, Spoth R, Redmond C. Unique influence of mothers and fathers on their children's antisocial behavior. Journal of Marriage \& Family. 2004; 66(3):762-778.

Lansford JE, Dodge KA, Pettit GS, Bates JE. A public health perspective on school dropout and adult outcomes: a prospective study of risk and protective factors from age 5 to 27 years. Journal of Adolescent Health. 2016; 58(6):652-658. [PubMed: 27009741]

Lawson G, Hook CJ, Hackman DA, Farah MJ. Socioeconomic status and the development of executive function: behavioral and neuroscience approaches. In: Griffin JA, McCardle P, Freund LS, Griffin JA, McCardle P, Freund LS, editorsExecutive function in preschool children: integrating measurement, neurodevelopment, and translational research. Washington, DC: American Psychological Association; 2014. 259-278.

Lengua LJ, Sadowski CA, Friedrich WN, Fisher J. Rationally and empirically derived dimensions of children's symptomatology: expert ratings and confirmatory factor analyses of the CBCL. Journal of Consulting and Clinical Psychology. 2001; 69(4):683-698. [PubMed: 11550734]

Longshore D, Chang E, Messina N. Self-control and social bonds: a combined control perspective on juvenile offending. Journal of Quantitative Criminology. 2005; 21(4):419-437.

Masten AS, Roisman GI, Long JD, Burt KB, Obradović J, Riley JR, et al. Developmental cascades: linking academic achievement and externalizing and internalizing symptoms over 20 years. Developmental Psychology. 2005; 41(5):733-746. [PubMed: 16173871]

Matsueda RL, Heimer K. Race, family structure, and delinquency: a test of differential association and social control theories. American Sociological Review. 1987; 52(6):826-840.

Maynard BR, Salas-Wright CP, Vaughn MG. High school dropouts in emerging adulthood: substance use, mental health problems, and crime. Community Mental Health Journal. 2015; 51(3):289-299. [PubMed: 25030805]

McAuley T, Chen S, Goos L, Schachar R, Crosbie J. Is the behavior rating inventory of executive function more strongly associated with measures of impairment or executive function? Journal of the International Neuropsychological Society. 2010; 16(3):495-505. [PubMed: 20188014]

McEvoy A, Welker R. Antisocial behavior, academic failure, and school climate: a critical review. Journal of Emotional and Behavioral disorders. 2000; 8(3):130-140. 
Meldrum RC, Barnes JC. Prenatal exposure to secondhand smoke and the development of self-control. Journal of Developmental and Life-Course Criminology. 2016; Advance online publication. doi: 10.1007/s40865-40016-40038-40861

Meldrum RC, Young JTN, Burt CH, Piquero AR. Maternal versus adolescent reports of self-control: implications for testing the general theory of crime. Journal of Criminal Justice. 2013; 41(1):24 32.

Moffitt TE. Life-course-persistent and adolescence-limited antisocial behavior: a 10-year research review and a research agenda. In: Lahey BB, Moffitt TE, Caspi A, editorsCauses of conduct disorder and juvenile delinquency. New York, NY: Guilford Press; 2003. 49-75.

Moffitt TE, Arseneault L, Belsky D, Dickson N, Hancox RJ, Harrington H, et al. A gradient of childhood self-control predicts health, wealth, and public safety. PNAS Proceedings of the National Academy of Sciences of the United States of America. 2011; 108(7):2693-2698.

Morgan AB, Lilienfeld SO. A meta-analytic review of the relation between antisocial behavior and neuropsychological measures of executive function. Clinical Psychology Review. 2000; 20(1): 113-156. [PubMed: 10660831]

Murray DW, Rosanbalm K, Christopoulos C, Hamoudi A. Self-regulation and toxic stress: foundations for understanding self-regulation from an applied developmental perspective, OPRE Report \#2015-21. Washington, DC: Office of Planning, Research and Evaluation, Administration for Children and Families, U.S. Department of Health and Human Services; 2015.

Muthén LK, Muthén BO. 1998-2012 Mplus user's guide, version 7. Los Angeles, CA: Muthén and Muthén; 2012.

Najaka SS, Gottfredson DC, Wilson DB. A meta-analytic inquiry into the relationship between selected risk factors and problem behavior. Prevention Science. 2001; 2(4):257-271. [PubMed: 11833928]

Nesbitt KT, Baker-Ward L, Willoughby MT. Executive function mediates socioeconomic and racial differences in early academic achievement. Early Childhood Research Quarterly. 2013; 28(4):774783.

Newcomb MD, Abbott RD, Catalano RF, Hawkins JD, Battin-Pearson S, Hill K. Mediational and deviance theories of late high school failure: process roles of structural strains, academic competence, and general versus specific problem behavior. Journal of Counseling Psychology. 2002; 49(2):172.

Noble KG, Norman MF, Farah MJ. Neurocognitive correlates of socioeconomic status in kindergarten children. Developmental Science. 2005; 8(1):74-87. [PubMed: 15647068]

Ogilvie JM, Stewart AL, Chan RCK, Shum DHK. Neuropsychological measures of executive function and antisocial behavior: a meta-analysis. Criminology. 2011; 49(4):1063-1107.

Patterson GR, DeBaryshe BD, Ramsey E. A developmental perspective on antisocial behavior. American Psychologist. 1989; 44(2):329-335. [PubMed: 2653143]

Piquero AR, Jennings WG, Farrington DP, Diamond B, Gonzalez JMR. A meta-analysis update on the effectiveness of early self-control improvement programs to improve self-control and reduce delinquency. Journal of Experimental Criminology. 2016; 12(2):249-264.

Pratt TC, Cullen FT. The empirical status of Gottfredson and Hirschi's general theory of crime: a metaanalysis. Criminology. 2000; 38(3):931-964.

Riccio CA, Gomes H. Interventions for executive function deficits in children and adolescents. Applied Neuropsychology: Child. 2013; 2(2):133-140. [PubMed: 23848245]

Riggs NR, Greenberg MT, Kusché CA, Pentz MA. The mediational role of neurocognition in the behavioral outcomes of a social-emotional prevention program in elementary school students: effects of the PATHS curriculum. Prevention Science. 2006; 7(1):91-102. [PubMed: 16572300]

Rumberger RW. Dropping out: Why students drop out of high school and what can be done about it. Cambridge, MA: Harvard University Press; 2011.

Sarsour K, Sheridan M, Jutte D, Nuru-Jeter A, Hinshaw S, Boyce WT. Family socioeconomic status and child executive functions: the roles of language, home environment, and single parenthood. Journal of the International Neuropsychological Society. 2010; 17(1):120-132. [PubMed: 21073770] 
Sirin SR. Socioeconomic status and academic achievement: a meta-analytic review of research. Review of Educational Research. 2005; 75(3):417-453.

Sutherland EH. Development of the theory [Private paper published posthumously]. In: Schuessler K, editorEdwin Sutherland on analyzing crime. Chicago: University of Chicago Press; 1973. 13-29.

Van Ryzin MJ, Stormshak EA, Dishion TJ. Engaging parents in the family check-up in middle school: longitudinal effects on family conflict and problem behavior through the high school transition. Journal of Adolescent Health. 2012; 50(6):627-633. [PubMed: 22626491]

Vazsonyi AT, Mikuška J, Kelley EL. It's time: a meta-analysis on the self-control-deviance link. Journal of Criminal Justice. 2017; 48:48-63.

Vega-Fernandez P, Zelko FA, Klein-Gitelman M, Lee J, Hummel J, Nelson S, et al. Value of questionnaire-based screening as a proxy for neurocognitive testing in childhood- onset systemic lupus erythematosus. Arthritis Care \& Research. 2014; 66(6):943-948. [PubMed: 24339409]

Wang MT, Fredricks JA. The reciprocal links between school engagement, youth problem behaviors, and school dropout during adolescence. Child Development. 2014; 85(2):722-737. [PubMed: 23895361]

Wardrop JL. Review of the California Achievement Tests, Forms E and F. In: Conoley JC, Kramer JJ, editorsThe tenth mental measurements yearbook. Lincoln, NE: Buros Institute, University of Nebraska Press; 1989. 128-133.

Wilens TE, Martelon M, Fried R, Petty C, Bateman C, Biederman J. Do executive function deficits predict later substance use disorders among adolescents and young adults? Journal of the American Academy of Child \& Adolescent Psychiatry. 2011; 50(2):141-149. [PubMed: 21241951]

Wright BRE, Caspi A, Moffitt TE, Silva PA. Low self- control, social bonds, and crime: social causation, social selection, or both? Criminology. 1999; 37(3):479-514.

Zhou Q, Chen SH, Main A. Commonalities and differences in the research on children's effortful control and executive function: a call for an integrated model of self- regulation. Child Development Perspectives. 2012; 6(2):112-121. 


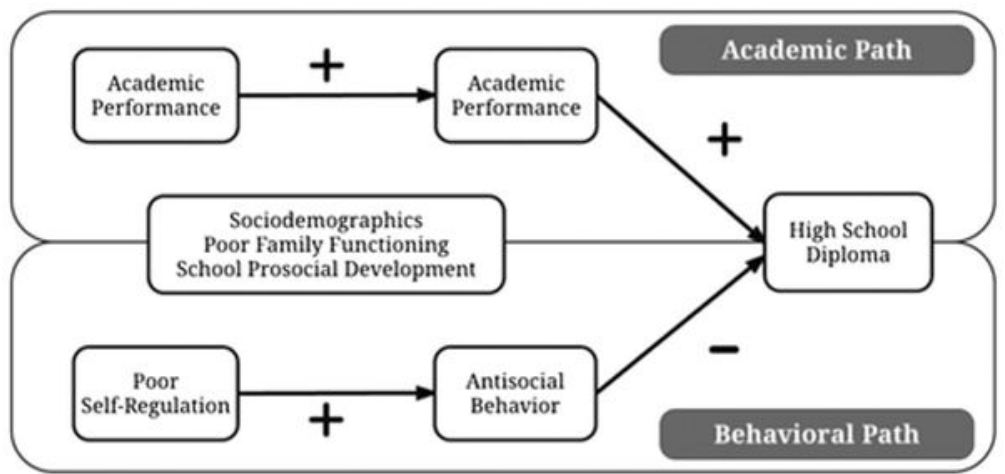

Figure 1.

Hypothesized academic and behavioral paths over time to obtaining a high school diploma. Both paths should be assessed concurrently and in the context of sociodemographic, family, and school factors. Pluses and minuses indicate positive and negative relationships among constructs respectively. 


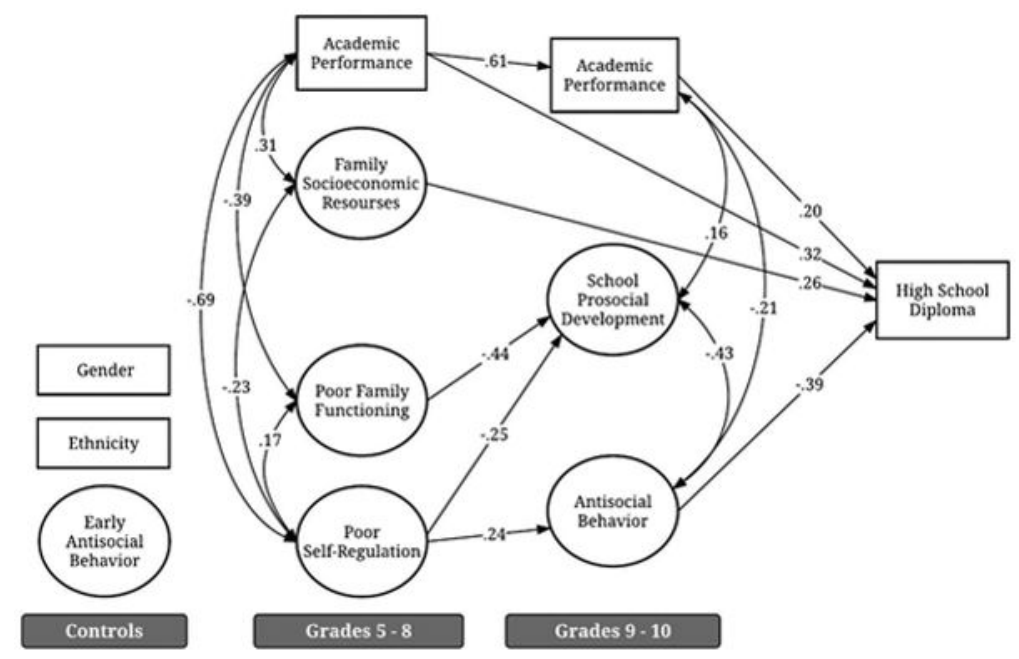

Figure 2.

Standardized coefficients for structural equation model assessing behavioral, academic, and social development mediators of academic performance with obtaining a high school diploma. Non-significant paths not shown (see Table 3 for a full list of estimates). The structural model showed adequate fit: $\chi^{2}=539(\mathrm{df}=201, \mathrm{p}<.001), \mathrm{CFI}=.923, \mathrm{RMSEA}=$. 046 (90\% CI: .041 - .050) and explained 61\% of the variance in obtaining a high school diploma. Indirect paths from grade 5-8 constructs to high school diploma were tested and found significant mediation of poor self-regulation by antisocial behavior and significant mediation of grade 5-8 academic performance by grade 9-10 academic performance. Results of all mediation tests are provided in Table 4. 


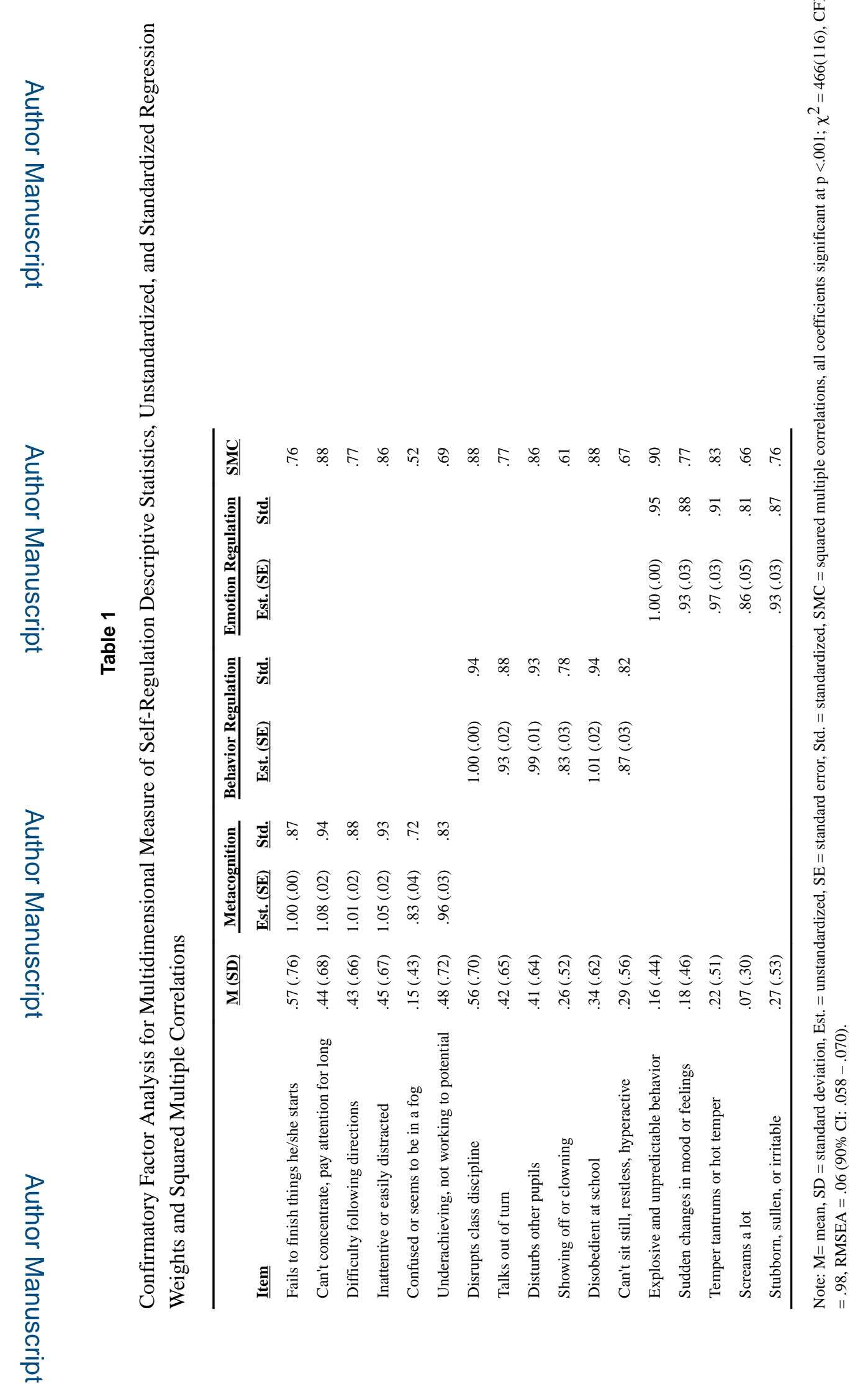

J Dev Life Course Criminol. Author manuscript; available in PMC 2018 September 13. 


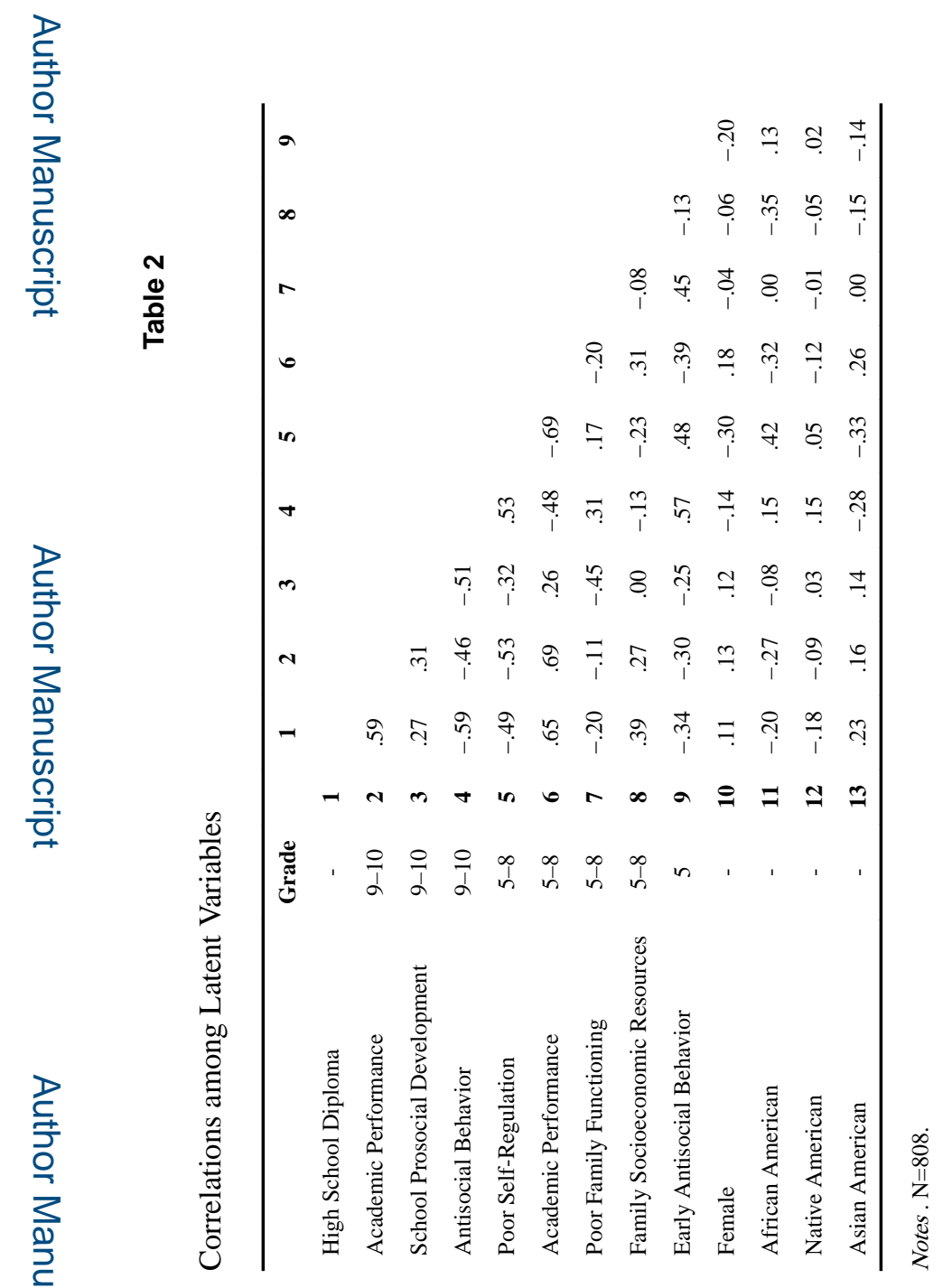




\section{Table 3}

Results of structural equation model predicting high school diploma

\begin{tabular}{|c|c|c|c|}
\hline & Est. & $\underline{\mathbf{S E}}$ & Std. \\
\hline \multicolumn{4}{|l|}{ Predictive Paths } \\
\hline \multicolumn{4}{|l|}{ High School Diploma } \\
\hline Antisocial Behavior & -.28 & .09 & $-.39^{* * * *}$ \\
\hline Academic Performance (Grade 9-10) & .20 & .07 & $.20^{* * * *}$ \\
\hline School Prosocial Development & -.06 & .08 & -.07 \\
\hline Poor Self-Regulation & .06 & .09 & .06 \\
\hline Academic Performance (Grade 5-8) & .32 & .09 & $.32^{* * *}$ \\
\hline Poor Family Functioning & -.06 & .07 & -.06 \\
\hline Early Antisocial Behavior & .10 & .10 & .10 \\
\hline Family Socioeconomic Resources & .26 & .06 & $.26^{* * *}$ \\
\hline Female & .08 & .11 & .04 \\
\hline African American & .23 & .13 & .10 \\
\hline Native American & -.14 & 1.22 & -.03 \\
\hline Asian American & .29 & .19 & .12 \\
\hline \multicolumn{4}{|l|}{ Antisocial Behavior (Grades 9-10) } \\
\hline Poor Self-Regulation & .32 & .10 & $.24^{* * * *}$ \\
\hline Academic Performance (Grade 5-8) & -.18 & .10 & -.13 \\
\hline Poor Family Functioning & .11 & .06 & .08 \\
\hline Early Antisocial Behavior & .49 & .08 & $.36^{* * *}$ \\
\hline Family Socioeconomic Resources & -.04 & .11 & -.03 \\
\hline Female & .04 & .15 & .01 \\
\hline African American & -.26 & .36 & -.08 \\
\hline Native American & .51 & 1.58 & .08 \\
\hline Asian American & -.47 & .53 & -.14 \\
\hline \multicolumn{4}{|l|}{ Academic Performance (Grades 9-10) } \\
\hline Poor Self-Regulation & -.09 & .06 & -.09 \\
\hline Academic Performance (Grade 5-8) & .61 & .04 & $.61^{* * * *}$ \\
\hline Poor Family Functioning & .05 & .04 & .05 \\
\hline Early Antisocial Behavior & -.04 & .05 & -.04 \\
\hline Family Socioeconomic Resources & .04 & .05 & .04 \\
\hline Female & -.03 & .06 & -.02 \\
\hline African American & -.09 & .20 & -.04 \\
\hline Native American & -.10 & .53 & -.02 \\
\hline Asian American & -.10 & .19 & -.04 \\
\hline \multicolumn{4}{|l|}{ School Prosocial Development } \\
\hline Poor Self-Regulation & -.29 & .11 & $-.25^{* *}$ \\
\hline Academic Performance (Grade 5-8) & .06 & .09 & .05 \\
\hline Poor Family Functioning & -.52 & .07 & $-.44^{* * * *}$ \\
\hline
\end{tabular}

J Dev Life Course Criminol. Author manuscript; available in PMC 2018 September 13. 


\begin{tabular}{|c|c|c|c|}
\hline & Est. & $\underline{\mathbf{S E}}$ & Std. \\
\hline Early Antisocial Behavior & .10 & .09 & .09 \\
\hline Family Socioeconomic Resources & -.08 & .12 & -.06 \\
\hline Female & .07 & .11 & .03 \\
\hline African American & .10 & .41 & .04 \\
\hline Native American & .25 & .87 & .05 \\
\hline Asian American & .18 & .42 & .06 \\
\hline Covariances & Est. & $\underline{\mathrm{SE}}$ & $\underline{\text { Std. }}$ \\
\hline \multicolumn{4}{|l|}{ Antisocial Behavior (Grade 9-10) with } \\
\hline Academic Performance (Grade 9-10) & -.15 & .04 & $-.21^{* * * *}$ \\
\hline School Prosocial Development & -.43 & .06 & $-.43^{* * *}$ \\
\hline \multicolumn{4}{|l|}{ Academic Performance (Grade 9-10) with } \\
\hline School Prosocial Development & .16 & .04 & $.22^{* * * *}$ \\
\hline \multicolumn{4}{|l|}{ Poor Self-Regulation with } \\
\hline Academic Performance (Grade 5-8) & -.69 & .04 & $-.69^{* * *}$ \\
\hline Poor Family Functioning & .17 & .04 & $.17^{* * *}$ \\
\hline Early Antisocial Behavior & .48 & .04 & $.48^{* * * *}$ \\
\hline Family Socioeconomic Resources & -.23 & .04 & $-.23 * * *$ \\
\hline Female & -.15 & .02 & $-.30^{* * *}$ \\
\hline African American & .19 & .01 & $.42^{* * *}$ \\
\hline Native American & .01 & .01 & .05 \\
\hline Asian American & -.14 & .02 & $-.33^{* * *}$ \\
\hline \multicolumn{4}{|l|}{ Academic Performance (Grade 5-8) with } \\
\hline Poor Family Functioning & -.39 & .05 & $-.39^{* * *}$ \\
\hline Early Antisocial Behavior & -.20 & .04 & $-.20 * * *$ \\
\hline Family Socioeconomic Resources & .31 & .04 & $.31^{* * * *}$ \\
\hline Female & .09 & .02 & $.18^{* * *}$ \\
\hline African American & -.14 & .02 & $-.32^{* * *}$ \\
\hline Native American & -.03 & .01 & $-.12^{* * *}$ \\
\hline Asian American & .11 & .02 & $.26^{* * *}$ \\
\hline \multicolumn{4}{|l|}{ Poor Family Functioning with } \\
\hline Early Antisocial Behavior & .45 & .04 & $.45^{* * *}$ \\
\hline Family Socioeconomic Resources & -.08 & .04 & -.08 \\
\hline Female & -.02 & .02 & -.04 \\
\hline African American & .00 & .02 & .00 \\
\hline Native American & .00 & .01 & -.01 \\
\hline Asian American & .00 & .02 & .00 \\
\hline \multicolumn{4}{|l|}{ Early Antisocial Behavior with } \\
\hline Family Socioeconomic Resources & -.13 & .05 & $-.13^{* *}$ \\
\hline Female & -.10 & .02 & $-.20 * * *$ \\
\hline
\end{tabular}

J Dev Life Course Criminol. Author manuscript; available in PMC 2018 September 13. 


\begin{tabular}{|c|c|c|c|}
\hline & Est. & $\underline{\mathbf{S E}}$ & Std. \\
\hline African American & .06 & .02 & $.13^{* *}$ \\
\hline Native American & .00 & .01 & .02 \\
\hline Asian American & -.06 & .02 & $-.14^{* *}$ \\
\hline \multicolumn{4}{|c|}{ Family Socioeconomic Resources with } \\
\hline Female & -.03 & .02 & -.06 \\
\hline African American & -.16 & .02 & $-.35^{* * *}$ \\
\hline Native American & -.01 & .01 & -.05 \\
\hline Asian American & -.06 & .02 & $-.15^{* * *}$ \\
\hline$\underline{\text { Latent Factors }}$ & Est. & $\underline{\mathrm{SE}}$ & $\underline{\text { Std. }}$ \\
\hline \multicolumn{4}{|l|}{ Antisocial Behavior (Grade 9-10) } \\
\hline Delinquency & .56 & .04 & $.84^{* * *}$ \\
\hline Substance Use & .36 & .03 & $.70^{* * * *}$ \\
\hline Deviant Peers & .33 & .02 & $.85^{* * *}$ \\
\hline \multicolumn{4}{|l|}{ School Prosocial Development a } \\
\hline Bonding & .39 & .02 & $.72^{* * *}$ \\
\hline Prosocial Opportunities & .34 & .02 & $.69^{* * *}$ \\
\hline Rewards & .18 & .03 & $.39^{* * *}$ \\
\hline \multicolumn{4}{|l|}{ Self-Regulation a } \\
\hline Emotion Regulation & .38 & .02 & $.64^{* * *}$ \\
\hline Metacognition & .54 & .03 & $.85^{* * *}$ \\
\hline Behavior Regualtion & .55 & .03 & $.80^{* * *}$ \\
\hline \multicolumn{4}{|l|}{ Poor Family Functioning } \\
\hline Family Conflict & .47 & .02 & $.82^{* * *}$ \\
\hline Poor Family Management & .40 & .02 & $.82^{* * *}$ \\
\hline Low Family Bonding & .33 & .02 & $.67^{* * * *}$ \\
\hline \multicolumn{4}{|l|}{ Family Socioeconomic Resources } \\
\hline Parental Education & .24 & .04 & $.58^{* * *}$ \\
\hline Free or Reduced Price Lunch & .38 & .02 & $.76^{* * *}$ \\
\hline Per Capita Family Income & .80 & .05 & $.85^{* * *}$ \\
\hline \multicolumn{4}{|l|}{ Early Antisocial Behavior } \\
\hline Delinquency & .65 & .08 & $.65^{* * *}$ \\
\hline Substance Use & .42 & .03 & $.53^{* * *}$ \\
\hline Deviant Peers & .31 & .03 & $.47^{* * *}$ \\
\hline
\end{tabular}

Notes. $\mathrm{N}=808$,

****

$\mathrm{p}<.001$,

p $<.01$,

p $<.05$,

J Dev Life Course Criminol. Author manuscript; available in PMC 2018 September 13. 
Est. $=$ unstandardized estimate, $\mathrm{SE}=$ standard error, Std. $=$ standardized estimate, $\chi^{2}=539(201), \mathrm{CFI}=.923, \mathrm{RMSEA}=.046(90 \%$ CI: $.041-$. 050), ethnicity variables compared to European Americans, $a=$ modification indices suggested freeing the covariance between indicators of latent variables. 


\section{Table 4}

\section{Mediation tests predicting high school diploma}

\begin{tabular}{|c|c|c|}
\hline & Est. & $\underline{\mathbf{S E}}$ \\
\hline \multicolumn{3}{|l|}{ Academic Performance (5-8) through } \\
\hline Academic Performance (9-10) & .12 & $.04^{* *}$ \\
\hline Antisocial Behavior (9-10) & .05 & .04 \\
\hline School Prosocial Development (9-10) & .00 & .01 \\
\hline \multicolumn{3}{|l|}{ Poor Self-Regulation (5-8) through } \\
\hline Academic Performance (9-10) & -.02 & .02 \\
\hline Antisocial Behavior (9-10) & -.09 & $.04^{*}$ \\
\hline School Prosocial Development (9-10) & .02 & .02 \\
\hline \multicolumn{3}{|c|}{ Family Socioeconomic Resources (5-8) through } \\
\hline Academic Performance (9-10) & .01 & .01 \\
\hline Antisocial Behavior (9-10) & .01 & .03 \\
\hline School Prosocial Development (9-10) & .00 & .01 \\
\hline \multicolumn{3}{|l|}{ Poor Family Functioning (5-8) through } \\
\hline Academic Performance (9-10) & .01 & .01 \\
\hline Antisocial Behavior (9-10) & -.03 & .02 \\
\hline School Prosocial Development (9-10) & .03 & .04 \\
\hline \multicolumn{3}{|l|}{ Early Antisocial Behavior (5) through } \\
\hline Academic Performance $(9-10)$ & -.01 & .01 \\
\hline Antisocial Behavior (9-10) & -.14 & $.05^{* *}$ \\
\hline School Prosocial Development (9-10) & -.01 & .01 \\
\hline
\end{tabular}

Notes. $\mathrm{N}=808$,

****

$\mathrm{p}<.001$,

*** $<$ <.01,

p $<.05$,

Est. $=$ standardized indirect estimate, $\mathrm{SE}=$ standard error, grades for each measure shown in parentheses. 